\title{
Receitas para o amor, por Aracy e João Guimarães Rosa
}

\author{
[ Recipes for love, by Aracy and João Guimarães Rosa
}

\section{Tânia Biazioli ${ }^{\mathrm{x}}$}

RESUMO -É este um estudo sobre os prazeres da mesa na vida e obra de Guimarães Rosa. Serão aqui analisados tanto os cadernos de receitas culinárias de sua esposa, Aracy, quanto os romances "Dão-Lalalão" e "Buriti”, de João Guimarães Rosa. Nossa hipótese era que as receitas poderiam trazer à tona a cozinha mineira. Descobrimos que a vida doméstica era o espaço onde se cultivava a culinária cosmopolita alemã, enquanto a literatura rosiana era o espaço onde se preservava a culinária regionalista mineira. Descobrimos também um convite das receitas para o amor, que aparece tanto nos nomes de doces, quanto nos romances de Noites do sertão. Afinal, a psicanálise mostra que o ato de comer busca a satisfação da fome e do amor. - PALAVRAS-CHAVE • Culinária; Guimarães
Rosa; psicanálise e literatura. - ABSTRACT · This is a study of the pleasures of the table in the life and work of Guimarães Rosa. It will be analysed here both Aracy's cookbook and the novels “Dão-Lalalão" and "Buriti” by João Guimarães Rosa. Our hypothesis was that the recipes could bring up the cuisine of Minas Gerais. We discovered that the home life was the space where German cosmopolitan cuisine was cultivated, while rosian literature was the space where Minas Gerais regionalist cuisine was preserved. We also discovered an invitation of the recipes for love, which appears in the names of sweets and in the novels of Noites do Sertão. After all, the psychoanalysis shows that eating seeks to satisfy hunger and love. · KEYWORDS · Culinary; Guimarães Rosa; psychoanalysis and literature.

Recebido em 30 de dezembro de 2018

Aprovado em 3I de janeiro de 2020

BIAZIOLI, Tânia. Receitas para o amor, por Aracy e João Guimarães Rosa. Revista do Instituto de Estudos Brasileiros, Brasil, n. 75, p. 18-35, abr. 2020.

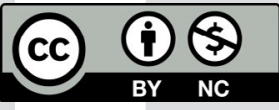

DOI: http://dx.doi.org/Io.II6o6/issn.23I6-90IX.voi75pI8-35

I Universidade de São Paulo (USP, São Paulo, SP, Brasil). 
Dr. J. Guimarães Rosa

Médico

Para a Ara:

Uso int.

Solução concentrada de amor - 5,0 grs.

Extracto fluido de paciência - 30 gotas

Tintura de espírito de justiça - 2,o grs.

Hydrolato de calma suave

- q. s. 150 c.c.

Te. I colher das de sopa, de $2 / 2$ horas, durante 3 meses.

Uso externo

Sorrisos para o amado

- IO,o grs.

Cara fechada para os outros - 5,o grs.

Tintura de gentileza $\quad-5$ gotas

Pó de bom humor

$-5,0$ grs.

Vaselina

$-30,0$ grs.

Uso explicado.

VI-VI-I939

Dr. João Babão.

(ROSA apud MINÉ \& CAVALCANTE, 2008, p. 430-43I). 
É este um estudo sobre os prazeres da mesa na vida e obra de Guimarães Rosa. Serão aqui analisados tanto os cadernos de receitas culinárias de Aracy, quanto a obra Noites do sertão, de João Guimarães Rosa ${ }^{2}$.

Este trabalho se insere no campo de estudos da alimentação. "Desde a Antiguidade pode-se dizer que a alimentação vem sendo objeto de atenção e conhecimento, devido à necessidade inescapável de ingerir alimentos para manter a vida”. É o que mostram Ulpiano Bezerra de Meneses e Henrique Carneiro (I997, p. IO-II) em “A história da alimentação: balizas historiográficas”. A alimentação despertou o interesse primeiro dos médicos e nutricionistas, mais tarde dos cientistas sociais. Os antropólogos e sociólogos contribuíram para que a alimentação deixasse de ser um tema complementar e se constituísse como um campo específico de estudos (POULAIN, 2006). Um marco importante para a consolidação da história da alimentação é a escola francesa dos Annales. Os primeiros trabalhos se basearam no conceito sobre vida material de Fernand Braudel, que abrangia os aspectos mais imediatos da sobrevivência humana: a comida, a habitação e o vestiário. A longa duração tornou-se a dimensão no interior da qual a alimentação revelaria sua permanência e sua mudança. Nesse primeiro momento, o interesse dos historiadores da alimentação voltava-se para o enfoque econômico (a produção e comercialização de certos produtos), porém os caminhos da Nova História e o contato mais íntimo com as ciências sociais deslocaram o interesse para o enfoque social (as formas de preparação e consumo desses produtos). Assim, os estudos da alimentação puderam se ampliar, da cultura material à imaterial, de modo a poder consolidar esse campo do conhecimento (ALGRANTI, 20Io). As contribuições de Gilberto Freyre (I996; 2006) e Câmara Cascudo (I983) sobre a formação da culinária brasileira a partir da influência dos ameríndios, portugueses e africanos puderam igualmente se desdobrar em trabalhos futuros sobre a alimentação, seguindo a tendência do movimento histórico internacional (CARNEIRO, 2003; SANTOS, 2005).

A leitura de um caderno de cozinha é muito bem-vinda ao estudioso da

2 Após eu ter sido convidada para preparar um café sertanejo em homenagem a Aracy em 20I2, soube que seus cadernos de receitas culinárias estavam arquivados no Instituto de Estudos Brasileiros da Universidade de São Paulo (IEB/USP). Esse convite deita raízes na minha participação junto à Oficina de Leitura Guimarães Rosa, que desenvolve atividades acadêmicas e artísticas em torno da vida e obra do escritor mineiro na universidade desde 2003. Parece ter alegrado a todos preparar uma mesa com comida típica mineira nos eventos literários “Virada Rosiana”, sobre a leitura contínua do romance Grande sertão: veredas, e “A Boiada, 60 anos”, sobre a leitura das cadernetas de viagem do escritor pelo sertão mineiro. Mas, ainda, era preciso estreitar os laços entre culinária e literatura rosiana. Para comemorar os 50 anos do IEB, colocaram-se à mesa iguarias do Grande sertão: veredas. Esse interesse em ler os cadernos de receitas culinárias de Aracy, apenas, dá continuidade a meu envolvimento com a literatura de Guimarães Rosa. A primeira versão deste texto, “Entre a culinária cosmopolita e a regionalista. Aracy e João Guimarães Rosa”, foi escrita para o curso de História da Alimentação, ministrado pela professora Leila Mezan Algranti na Universidade Estadual de Campinas (Unicamp), no segundo semestre de 20I2. Quando esse trabalho foi apresentado na Oficina de Leitura Guimarães Rosa, em agosto de 20I3, visitamos o acervo sobre a culinária de Aracy de Carvalho Guimarães Rosa no IEB/USP, convidamos sua família para lembrar as receitas favoritas dos Rosa e oferecemos um café inspirado nos cadernos culinários de Aracy e na literatura de Guimarães Rosa. 
alimentação, mas não se pode tomá-lo por si só como um testemunho das práticas alimentares do passado. Pois os manuscritos culinários se inspiram em tradições que os precederam, como alerta Bruno Laurioux (20I5), ao copiar receitas de outros tempos e lugares. É assim que o Cozinheiro nacional - o primeiro livro que pretendia apresentar uma "cozinha em tudo brasileira”, publicado no final do século XIX indica as carnes dos mamíferos que povoam nossas matas, as aves que habitam nossos climas, os peixes que sulcam nossos rios e mares. Porém, Carlos Dória (2008) observa no prefácio do livro que os produtos da flora e fauna do país eram preparados de um modo todo francês. $\mathrm{O}$ estudo dos títulos das receitas também possibilita uma análise muito interessante ao revelar nomes de pessoas ou de regiões. Mas isso só não basta. É preciso também estudar o conteúdo das receitas. Pois as receitas escritas em diferentes épocas, segundo Eliane Abrahão (20I6), permitem reconstituir os ingredientes e técnicas culinárias, que evoluem com o tempo.

$\mathrm{Na}$ receita que o médico Dr. João Babão prescreveu para a Ara, havia alguns ingredientes que não podiam faltar, como amor, paciência, espírito de justiça e calma suave. Eram também indicados sorrisos para o amado e cara fechada para os outros, bem como gentileza e bom humor. A vaselina aparece rasurada no original, para preservar a intimidade do casal. Aracy e João Guimarães Rosa pareciam intuir que as receitas poderiam ser trocadas pelos amantes na busca do prazer. Desde os tempos mais antigos, as receitas eram utilizadas tanto pelos médicos, quanto pelos cozinheiros para tratar da dieta dos prazeres. Tempos mais tarde, a psicanálise pôde compreender que o ato de comer busca satisfazer a fome e o amor. E, até mesmo, a necessidade de conservação da vida extrai sua força da sexualidade³.

O casal se conheceu na Alemanha hitlerista, quando trabalharam juntos no consulado brasileiro de Hamburgo. Aracy é conhecida tanto por ter vivido uma história de amor com João Guimarães Rosa, quanto por ter ajudado na fuga dos judeus da Alemanha nazista. Pouco conhecidas são a vida e a obra de Guimarães Rosa à mesa.

Temos uma grande quantidade de material disponível para a pesquisa sobre a culinária de Aracy de Carvalho Guimarães Rosa no Arquivo do Instituto de Estudos Brasileiros da Universidade de São Paulo (IEB/USP). Desde os cadernos de receitas às receitas recortadas de revistas ou embalagens de produtos, que foram guardadas soltas ou coladas em folhas de caderno. Desde o cardápio do seu primeiro casamento com Johannes Tess aos cardápios recolhidos a bordo de navios.

Nossa hipótese era que as receitas culinárias de Aracy poderiam trazer à tona a vida doméstica e familiar de Guimarães Rosa, marcada pela cozinha mineira 4 . Mas

3 A psicanálise pôde ainda mostrar a relação entre a moral alimentar "civilizada" e a doença nervosa contemporânea. Não é à toa a predominância de transtornos alimentares na contemporaneidade. A busca do prazer à mesa chamou menos a atenção dos psicanalistas do que a recusa do prazer alimentar, devido à migração dos valores morais da sexualidade para a alimentação. Ver: Herrmann; Minerbo, I998; Weinberg, 2008; Carvalho, 2012.

4 Isso é o que é possível compartilhar ao sentarmos à mesa com personagens emblemáticos da nossa cultura, como Gilberto Freyre e Monteiro Lobato. As receitas que suas esposas trocaram com familiares e amigos apresentam, respectivamente, a culinária tradicional nordestina e caipira. Ver: Lody, 2004; Camargos; Sacchetta, 2008. 
existe uma comida típica mineira?5 É o que se pergunta Eduardo Frieiro (I982), em Feijão, angu e couve. A resposta é sim e não. Sim, porque é possível reconhecer uma constante das preferências alimentares dos habitantes de Minas. Não, porque tais preferências não são exclusivas de sua gente. Desde os primórdios do povoamento até os dias atuais, existe uma constante na tríade do feijão, angu e couve. Os pratos típicos mineiros são o tutu de feijão com torresmos (ou linguiça), o lombo de porco assado e a couve fina. Acrescente-se a galinha ao molho pardo com angu e quiabo. Todos pratos mineiros, sem serem eclusivos de Minas. Convém dizer que a Receita de mineiridade, segundo Mônica Abdala (2007), é a construção da imagem do mineiro a partir da cozinha. Isso é evidente no relato dos cronistas e viajantes, desde o apogeu da mineração até a ruralização da economia. Não é só isso. Existiu uma política de governo para a preservação da culinária típica mineira, como aparece no livro de receitas Fogão de lenha, escrito por Maria Stella Libanio Christo.

Descobrimos, porém, que o sentido da culinária de Aracy reside numa composição entre a cozinha alemã e a cozinha brasileira. Isso é o que encontramos ao analisar tanto seus cadernos de receitas, como suas receitas favoritas. À medida que nos aproximamos de Guimarães Rosa, despontou a cozinha mineira. É o que aparece de maneira singela nos seus pratos prediletos e com toda sua força nos romances "Dão-Lalalão" e "Buriti”. Descobrimos, também, um convite das receitas ao amor, presente tanto nos nomes de doces e bebidas dos cadernos de cozinha, quanto nos romances de Noites do sertã $0^{6}$.

\section{Aracy de Carvalho Guimarães Rosa: entre o amor e a guerra}

Antes mesmo de iniciar a leitura de seus cadernos de receitas, é importante conhecer um pouco da história de Aracy para compreendermos a formação de seu gosto gastronômico. Aracy Moebius de Carvalho era filha de mãe alemã e pai português. A família tinha residência em São Paulo, aonde ela estudou num colégio de moças no bairro de Perdizes. Depois, fez o curso ginasial na Suíça, aprendendo diversas línguas. Casou-se muito jovem, aos I7 anos, com o descendente de alemão Johannes Tess. Mas se desquitou com 26 anos, indo com a mãe e o filho de 3 anos para a Europa hitlerista

5 A tradição mineira de forno e fogão, sempre tão lembrada no lugar da cozinha paulista, pode vir a reconhecer a herança de um passado comum. A culinária caipira é o resultado do ajustamento do colonizador português ao novo mundo, no contato com os indígenas. A expansão geográfica dos bandeirantes pelo território resultou num lençol de comida caipira que abrangeu partes de Minas, Goiás e Mato Grosso. A constância do milho e a carne de porco preferida à de boi indicam um rancho caipira. Muito longe de serem primas distantes que mal se conversam, a mesa mineira é antes filha da paulista. Ver: Candido, 2001.

6 Agradeço à historiadora Eliane Morelli Abrahão, da Universidade Estadual de Campinas (Unicamp), pela indicação do acervo sobre a culinária de Aracy no Arquivo do IEB/USP. Agradeço, também, à Oficina de Leitura Guimarães Rosa, representada à época por seus coordenadores, professor Heinz Dieter Heidemann, da Faculdade de Filosofia, Letras e Ciências Humanas (FFLCH/USP), que traduziu as receitas alemãs, e Rosa Haruco Tane, que me colocou em contato com a família de Aracy para que eu pudesse descobrir as receitas prediletas do casal. 
em I936. Aracy e João Guimarães Rosa conheceram-se dois anos depois, quando trabalhavam como funcionários no consulado brasileiro de Hamburgo (Figura I).

É comum aproximarem-se de Aracy, em especial, para tratar da história de amor que ela viveu com João Guimarães Rosa e da ajuda que ofereceu aos judeus na Alemanha nazista.

Aracy é conhecida como "mulher, amante, amiga e companheira" por João Guimarães Rosa. É o que nos mostra a pesquisa de Elza Miné e Neuma Cavalcante (2008, p. 426) sobre as cartas inéditas trocadas pelo casal. Assim, lemos nas anotações de I942:

Serás tudo para mim: mulher, amante, amiga e companheira. Sim, querida, hás de ajudar-me a escrever os nossos livros. Tu mesma não sabes o que vales. Eu sei. Serás, além de inspiradora, uma colaboradora valiosa, apesar ou talvez mesmo por não teres pretensões de “literata pedante”. (ROSA apud MINÉ; CAVALCANTE, 2008, p. 426).

Essas cartas de amor revelam ainda o papel de Aracy como leitora privilegiada da obra rosiana. Em entrevista concedida a Gilberto Cavalcanti, declara Aracy ter especial carinho por Grande sertão: veredas, que lhe tinha sido dedicado e cuja "feitura" ela tinha acompanhado "tin-tin por tin-tin, desde o seu início":

À medida que os capítulos ficavam prontos, eram lidos para mim. Sagarana é outro que gosto imensamente. No dia que ficou composto, mandou-nos o editor, de imediato, alguns exemplares. Joãozinho não estava em casa. Comprei então rosas e cerquei-as com os livros. (ROSA, A. I965, p. 5).

Não é à toa que Guimarães Rosa escreve em I946: "Para mim tuas cartas são como marmelada, doce de laranja, aipim, manjar branco, artigo elogiando 'Sagarana' no suplemento do jornal... Oh, Ara, que feitiço é esse?” (ROSA apud MINÉ; CAVALCANTE, 2008, p. 432). Ou, ainda, anota no mesmo ano: "Os outros eu conheci por ocioso acaso. A ti vim encontrar porque era preciso" (ROSA apud MINÉ; CAVALCANTE, 2008, p. 443).

Aracy é também lembrada, como "O Anjo de Hamburgo", por ter ajudado na fuga de judeus para o Brasil durante a Alemanha nazista. Para manter viva essa memória, os judeus expressaram sua gratidão e a homenagearam na Avenida dos Justos, no Bosque da Vida, em Israel. Seu nome também está incluído no Memorial do Holocausto, em Washington. 


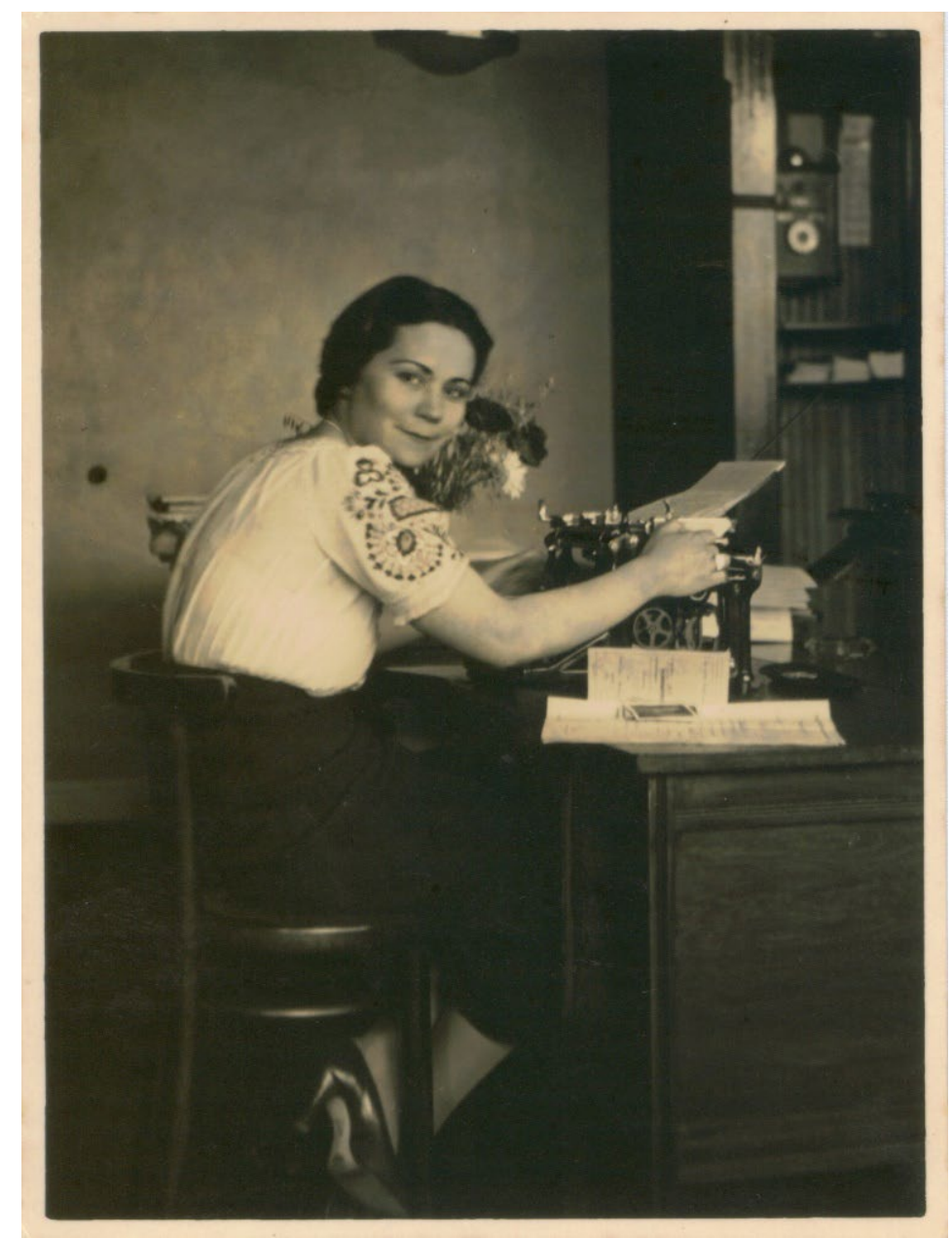

Figura I - Aracy no consulado brasileiro de Hamburgo. Acervo Família Tess

A historiadora Mônica Schpun (20II) mostra em seu livro Justa - Aracy de Carvalho e o resgate dos judeus que, ao trabalhar na divisão de passaportes do consulado brasileiro em Hamburgo, Aracy ajudou a conceder inúmeros vistos aos judeus, ignorando as instruções em contrário impostas pelo governo de Getúlio Vargas. Aracy colocava os documentos entre a papelada para que o cônsul pudesse assinar os vistos. Assim, conseguiu os passaportes sem o J em vermelho dos judeus.

E não fez só isso. Forjava atestados de residência para poder atender judeus das cidades onde os diplomatas eram menos prestativos. Chegou mesmo a transportar um judeu até a fronteira, só escapando por conta da placa do carro consular. Visitava judeus para levar mantimentos. Guardava seus bens a fim de repatriá-los para fora do país, evitando que fossem roubados pelos nazistas.

Guimarães Rosa teve, com Aracy, um modelo de coragem e posicionamento diante 
das injustiças, ajudando a moldar seu ideal de diplomacia. Ao falar sobre suas ações em Hamburgo, dizia que como "homem do sertão" não podia presenciar injustiças?.

\section{DA CULINÁRIA COSMOPOLITA À CULINÁRIA REgIONALISTA}

Ao dar início à leitura dessa série de cadernos de cozinha ${ }^{8}$, o que primeiro salta aos olhos é a presença lado a lado de receitas alemãs e brasileiras. As receitas aparecem escritas nas duas línguas: ora em alemão, ora em português. Às vezes, ocorre uma mistura dos idiomas na escrita do título da receita, dos ingredientes e do preparo. Uma confusão de línguas até. Muito típico entre as famílias de imigrantes.

À medida que vamos lendo uns após os outros os cadernos, notamos uma ascensão crescente das receitas brasileiras e uma queda das receitas alemãs.

Deitemos primeiro o olhar nas receitas alemãs. Encontramos um equilíbrio entre pratos salgados e doces. Entre os salgados, temos a constância dos "Gulasch", "Käsestangen”, “Gekochte Kartoffelknödel”, "Rohe Kartoffelknödel”, “Markknödel”. Aqui e ali, algumas variações. "Herings Salat", "Sandwiches fur Teetisch", "Speckkuchen”, "salsicha ou salsichão recheado", "repolho roxo", "Spätzle”. Entre os doces, temos uma variedade de "Kuchen”, "Pudding”, “Torte”, "Plätzchen”. Mais algumas especialidades, como "Windbentel”, "Strudelteig”, "Kokosmussmakronen”, "Makronen”, "Schokoladen Creme”, "Zitronenspeise”, "Orangenmarmelade”.

Vejamos, agora, as receitas brasileiras. Em geral, existe um equilíbrio maisque-perfeito entre pratos salgados e doces. Exceção seja feita ao caderno culinário, escrito na década de I940, onde é notável a presença exuberante da doçaria brasileira. Os cadernos apresentam receitas de pães, empadas e pastéis. E vai além. Berinjela frita, manjar de camarão, cuscuz de tapioca, rosbife, picadinho caipira, frango com curry. Todos os cadernos contêm um bom número de bolos, pudins, tortas e biscoitos. Mas não só isso. Papo de anjo, ambrosia. Quindim, cocada e pé-de-moleque.

7 Sobre a temática da guerra, ver ainda “O diário de guerra de João Guimarães Rosa”, organizado pelos pesquisadores Eneida Souza, Georg Otte e Reinaldo Marques, do Documento do Acervo de Escritores Mineiros da Universidade Federal de Minas Gerais; o documentário Outro sertão (2013), dirigido por Adriana Jacobsen e Soraia Vilela, que trata da atuação de Guimarães Rosa na Alemanha nazista; e o documentário Esse viver ninguém me tira (20I4), dirigido por Caco Ciocler, sobre a ajuda de Aracy Moebius de Carvalho aos judeus alemães para emigrarem ao Brasil a fim de escaparem do nazismo.

8 Somam ao todo cinco, os cadernos de receitas. Um manuscrito em São Paulo em I942, outro no Rio de Janeiro em I973. Existe um caderno sem data, que parece ter passado a limpo receitas guardadas soltas, sobretudo, das décadas de 40 e 50. Outro foi um presente, recebido de Terezinha de Jesus em I966, no qual Aracy acrescentou umas poucas receitas nas páginas em branco. Um caderno não foi para a frente.

9 Gulasch, palitos de queijo, bolinho de batata cozido, bolinho de batata crua, bolinho de tutano. Sanduíche para mesa de chá, salada de arenque, bolo de carne, massa para macarrão. Bolo, pudim, torta, biscoito. Sacola de vento, massa de strudel, doce de coco, doce de amêndoas, creme de chocolate, creme de limão, marmelada de laranja. 
Bombocado de queijo, brevidade. Docinhos, balas e bombons. Geleia e creme de laranja. Gelatina. Mousse de coco e de manga. Pavê.

Esses cadernos de receitas seguem, ainda, a tendência da mesa brasileira em incorporar a cozinha dos imigrantes. Exemplos maiores são a cozinha árabe, com seu "pão sírio" e "quibe", e a cozinha italiana, com seu "macarrão" e sua "pizza".

Mais significativa é a forte influência da gastronomia francesa nesses manuscritos culinários. Ao lado das familiares receitas brasileiras, vemos surgir estrangeiras receitas de origem francesa: "Suflé", "Mousse de foie gras", "Panqueca" "Strogonoff", "Petit fours" e "Crépe suzette”. São receitas francesas que se ajustaram ao paladar brasileiro. É o mesmo que ocorre com as receitas alemãs. Os pratos salgados - Gulasch, bolinhos de queijo, batata e tutano - pertencem à cozinha familiar alemã. Os pratos doces - cremes e tortas - recebem a influência da cozinha estrangeira francesa.

Isso tudo revela a tendência da mesa brasileira de se espelhar na gastronomia francesa, que estava em voga. Tanto é assim que o Hotel Flamengo servia um menu totalmente à francesa, durante a década de I920, na praia do Rio de Janeiro. Os cardápios de navios alemães, entretanto, eram mais fiéis a sua cozinha nacional (Figura 2).
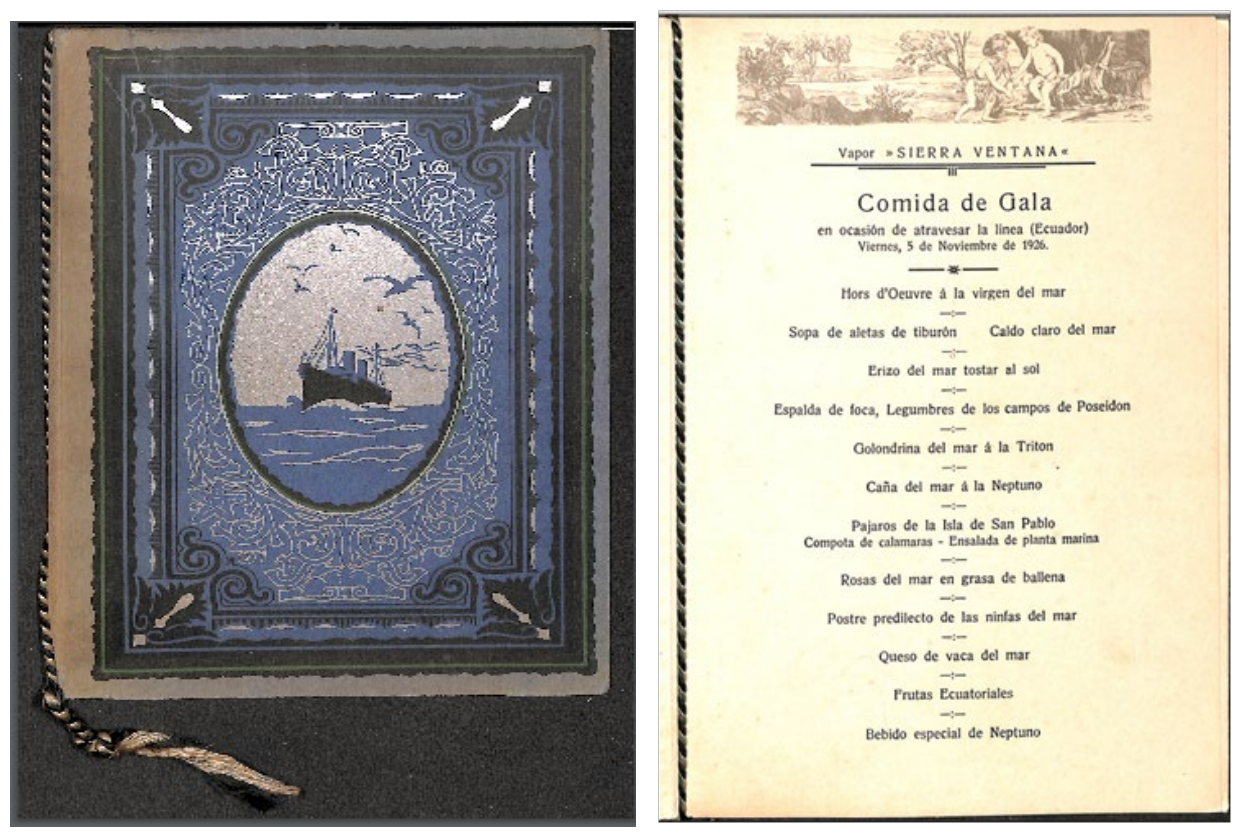

Figura 2 - Partes de cardápio bem-humorado do vapor Sierra Ventana para a travessia da Linha do Equador, 5/II/I926. Arquivo IEB/USP, Fundo Aracy de Carvalho Guimarães Rosa, código de referência ACGR-I367 
As preferências à mesa dos Rosa revelam a presença da culinária alemã e da culinária mineira habitando o seio do casal ${ }^{\text {To }}$. De um lado, Aracy tinha o prato alemão Gulasch como seu predileto. De outro, Guimarães Rosa preferia os pratos simples, "comida típica que mineiro gosta": frango com quiabo e tutu de feijão!

Encontramos a receita de Gulasch (Figura 3) em dois cadernos distintos. Primeiro a receita aparece escrita em alemão, depois é traduzida para o português ${ }^{\text {Ir. }}$. Eis o preparo do prato:

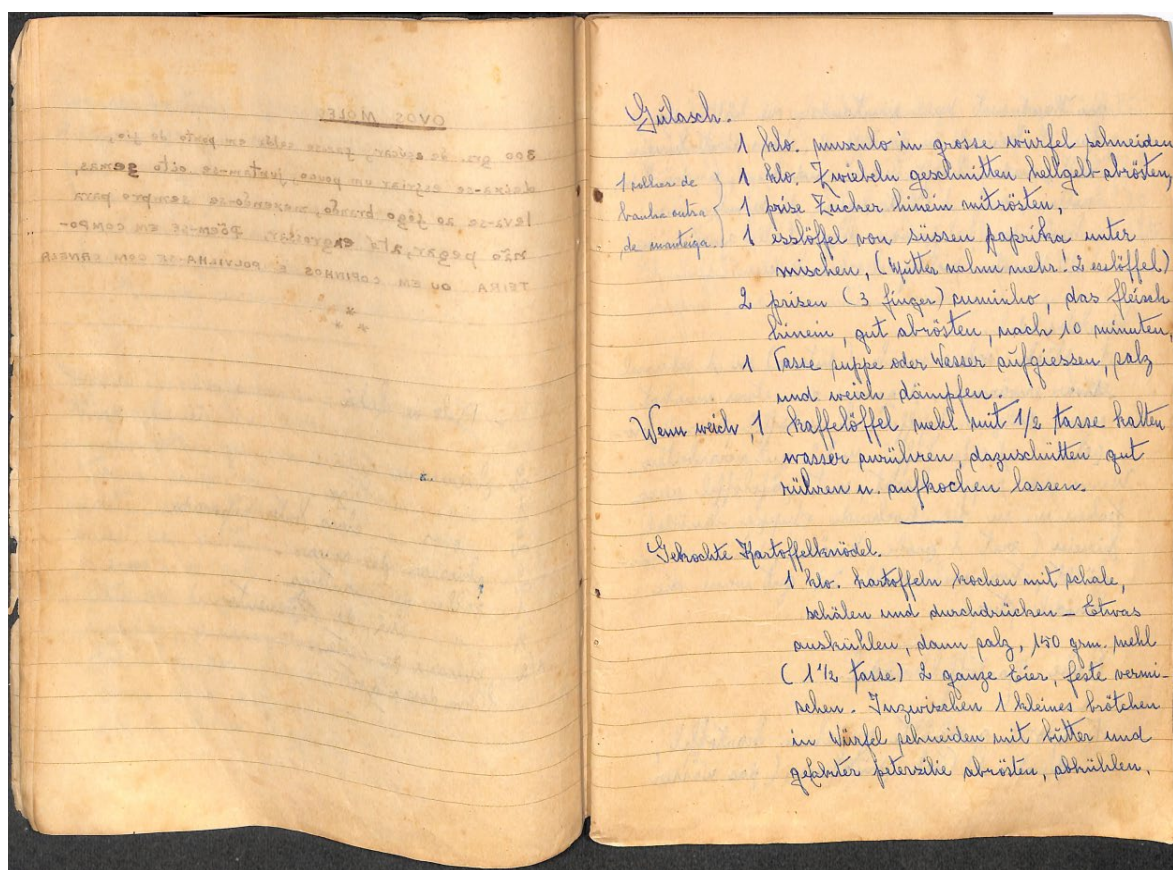

Figura 3 - Receita de Gulasch em alemão. Arquivo IEB/USP, Fundo Aracy de Carvalho Guimarães Rosa, código de referência ACGR-0046

Io Para descobrir quais eram as receitas prediletas do casal, recolhemos as memórias da família. Sophia Tess entrevistou, a nosso pedido, Eduardo e Bia Tess, filho e nora de Aracy.

II No último caderno, encontramos o prato húngaro "Gulash" escrito em português: "O que é necessário: I quilo de carne - $1 / 2$ quilo de cebola - I quilo de tomates sem peles e caroços - I copo de água - I folha de louro - I maço de cheiro-verde - I dente de alho - I colher de gordura - I colher de sopa rasa de 'paprika' - I xícara de creme de leite fresco - sal necessário. Como você deve fazer: limpar a carne, cortar em pequenos cubos. Picar a cebola e o alho. Colocar na panela com gordura quente. Juntar a carne. Misturar sem refogar. Cobrir a panela, diminuir o fogo e deixar assim durante I5 minutos. Acrescentar os tomates amassados, o cheiro verde picado e a 'paprika'. Temperar de sal. Regar com água. Cozinhar em fogo muito lento durante 2 ou 3 horas. No momento de servir, juntar o creme de leite. O 'goulash' pode ser servido com polenta, talharim, 'nhoque', batatas cozidas ou arroz branco" (ARQUIVO IEB/USP, Fundo Aracy de Carvalho Guimarães, código de referência ACGR-0047). 
A leitura dos cadernos de receita culinária pôde revelar a formação do gosto de Aracy de Carvalho Guimarães Rosa. A vida familiar parecia marcada, a um só tempo, pela tradição das cozinhas alemã e brasileira. Isso tudo não é de espantar. $\mathrm{O}$ gosto gastronômico parecia determinado pela história de família e migração, nos lugares de origem e destino. Verdade que o gosto de Aracy pela cozinha alemã pode ser melhor compreendido pela sua origem familiar alemã, pela educação ginasial na Suíça e pelo trabalho no consulado brasileiro em Hamburgo. Verdade também que o gosto pela cozinha brasileira se deve ao fato de ela ter nascido e vivido boa parte de sua vida no Brasil. Ainda, o gosto gastronômico parecia determinado por um fator de distinção social. Tudo se passa como se os cadernos de cozinha brasileira estivessem com os olhos voltados para o estrangeiro, pois a gastronomia francesa estava em voga. Mas não é só isso. As receitas prediletas de Aracy revelam o gosto pela culinária cosmopolita ao privilegiar o prato alemão Gulasch. Enquanto os pratos favoritos de Guimarães Rosa dão mostras de uma culinária regionalista ao destacar os mineiríssimos frango com quiabo e tutu de feijão.

\section{O CONVITE DAS RECEITAS AO AMOR}

Escrever o próprio caderno de cozinha significa recolher receitas de familiares e amigos. Talvez isso advenha de uma troca de receitas ao saborear um prato na casa de gente conhecida. Assim, é possível ver ao lado do nome da receita a sua procedência: "Frau Jensen”, “Frau Fromm”, “Dona Margarida”, “Lourdes”, “Mamãezinha”, “Tia Palmyra”, “Tita de Carvalho”, “D. Laura”, “Anni Kreutzberg!”. E tantas outras. Quem serão essas mulheres que Aracy conheceu e com elas trocou receitas? Nessa lista de mulheres, encontramos a simpatia de Aracy pelos judeus. Onde se lê "Dona Margarida", na massa de tutano para doce e salgado, podemos ler "Margarethe Levy". Aracy a salvou da morte, iniciando-se um forte laço de amizade. Sem filhos para apoiá-la, foi o carinho da família Tess que amparou "Dona Margarida” na velhice. Outros nomes de receitas dizem respeito a um lugar de origem. São especialidades e raridades das queridas cidades de Viena, Frankfurt, Hamburgo, Colônia, Nauheim, Traunstein, Eger. Quando se quer, por exemplo, comer à moda da Escandinávia, é possível trazer um pouco do lugar distante para perto. Algumas receitas ainda foram recortadas de jornal ou revista e coladas no caderno. Outras são cópias de livro ou folheto de cozinha: "Kochbuch meiner Mutter", “Oranier - Kochbuch”, “A.B.C. der Küche”, “Gaskalender”, "Nhá Benta”.

A escrita da receita separa, de um modo muito mais informal do que formal, ingredientes, modos de fazer e notas. Sem contar aquelas receitas que ensinavam como se preparava o prato ao mesmo tempo em que indicavam os ingredientes e suas quantidades. Eliane Abrahão (20I6) mostra em "A escrita culinária" que esse estilo perpetuou-se ao longo dos séculos, desde os manuscritos medievais de Apicius até a época moderna com Carême. Isso em nada se parece com os livros de cozinha atuais que, desde o início do século passado, explicitam minuciosamente as etapas do processo culinário para quem não tem nenhuma intimidade com o ato de cozinhar. A maneira de transmitir o saber da cozinha sofreu mudanças ao longo do tempo. 
Antes os manuscritos culinários eram bastante sucintos, pois podiam contar com uma experiência prévia que passava de boca em boca. Após o declínio da tradição, as receitas passaram a ser transmitidas de geração em geração por meio de uma escrita bastante detalhada.

Em geral, os nomes das receitas indicam o tipo do prato acompanhado pelo ingrediente principal. Temos assim bolos e pudins de coco e de queijo, de fubá e de aipim com coco. Bolo de milho, de cenoura e de abacaxi. Bolo de nozes e de castanha de caju. O simples pudim de pão, de leite ou de laranja. O requintado pudim de ameixas ou de castanhas. Torta de limão, de abacaxi e de maçã. Biscoito de cerveja.

Um capítulo à parte é composto pela doçura de alguns nomes de doces. "Lua de mel", "Amôr", "Bolo 3 amôres", "Docinhos", "Beijinhos", "Gelatina sonho cor de rosa” Gilberto Freyre (2006), no livro Casa-grande er senzala, surpreende estímulos ao amor e à fecundidade na culinária colonial brasileira. Os velhos nomes de quitutes e gulodices fazem recordar "a vibração erótica, a tensão procriadora que Portugal precisou de manter na sua época intensa de imperialismo colonizador. [...] Mesmo nos nomes de doces e bolos de convento, fabricados por mão seráficas, de freiras, sente-se às vezes a intenção afrodisíaca" (FREYRE, 2006, p. 330). É o que encontramos nos cadernos de receitas de Aracy em tom de prosa celestial: "Papos de anjos", "Bolo de anjo”. Gilberto Freyre (I997) sugere, no Prefácio à $3^{a}$ edição de Açúcar, que os nomes de doces, entretanto, "parecem nunca se tornarem irônicos, maliciosos, fesceninos ou anedóticos como os de cachaças ou aguardentes" (FREYRE, I997, p. 49). Afinal, doces e aguardentes destinam-se a um paladar e a um público muito diferente. "Têm antepassado ou avó comum - o açúcar da cana - mas são primos ou parentes que quase nunca se falam. Separados. Antagônicos. Odeiam-se, até. Ninguém bebe cachaça comendo bolo, doce ou biscoito" (FREYRE, 2006, p. 49). Os nomes das batidas nos cadernos de receita de Aracy, por sinal, não têm nada mesmo de angelical. É até mesmo muito carnal e tudo vai se esquentando: "Suor de virgem", "Meia de seda", "Dedo ouro", "Motor de arranque”, "Foguete", “Guindaste”. As batidas esquentam graças a muita cachaça, amendoim e ovos de codorna.

\section{Batida "Guindaste”}

$1 / 2$ litro de aguardente -250 grs. de creme de amendoim - 6 ovos de codorna -500 grs. de suco de maracujá - 2 colheres de leite condensado; tudo batido em liquidificador, e depois de coado, adoçado e rebatido com gelo picado no liquidificador, antes de servir. (ARQUIVO IEB/USP, Fundo Aracy de Carvalho Guimarães Rosa, código de referência ACGR-0047).

As dicas na receita dão um ar vivo ao caderno de cozinha. É possível pressentir a presença daqueles que por ali passaram, folheando suas páginas, testando receitas e tomando notas. Em geral, aparecem ao final como acréscimos preciosos daqueles que experimentaram a receita e têm algo a dizer. As notas poderão apontar para a aprovação da receita. "Fiz_ótimo levou ao forno mais ou menos 40 minutos".

I2 Nas transcrições foi mantida a grafia original. 
Também, poderão discorrer sobre o tempo de preparo e rendimento das receitas. "(Demora!) É um pudim gostoso e que rende muito." "Basta pôr uma colher em cada forma_cresce muito." "Dá um bolo grande_pode-se fazer a metade." Ou, ainda, sugerir uma substituição do ingrediente. "Em vez de lata de abacaxi é melhor o suco de abacaxi fresco!" Às vezes, um simples riscar de cruzes poderá indicar um prato favorito entre os de casa. Em "Duas receitas de bolo de cenouras da Mamãe", uma dúvida bem-humorada se impõe: "qual a certa?".

Assim, os cadernos de receita puderam revelar um convite ao amor. A psicanálise mostra que o ato de se alimentar serve para atender às necessidades não só da nutrição, de modo a assegurar a conservação da vida, mas também da satisfação sexual. Sigmund Freud (20I6), nos "Três ensaios sobre a teoria da sexualidade", apresenta a gênese do prazer oral na relação do bebê com o seio da mãe. A criança, ao chupar o dedo, busca a satisfação de um prazer, já vivido e agora lembrado. Ela quer repetir o prazer de mamar no seio da mãe.

Quem vê uma criança largar satisfeita o peito da mãe e adormecer, com faces rosadas e um sorriso feliz, tem que dizer que essa imagem é exemplar da satisfação sexual na vida posterior. Então a necessidade de repetir a satisfação sexual se separa da necessidade de nutrição. (FREUD, 20I6, p. 86).

Freud destaca que a satisfação do prazer oral se apoia primeiro na necessidade de alimento, que serve à conservação da vida, para depois se tornar independente dela. Não é à toa que o verbo "comer" em português tem dois sentidos. Um dos sentidos do verbo é alimentar-se, o outro sentido, fazer amor. Os nomes dos doces nos cadernos culinários mostram o convite das receitas ao amor, mas não chegaram a se tornar tão sensuais quanto os nomes das bebidas.

\section{RECEITAS PARA O AMOR DE ROSA}

Ao invés de encontrarmos os pratos mineiros na vida doméstica e familiar de Guimarães Rosa, foi preciso esperar para reencontrá-los na literatura. Talvez, comer a comida familiar do lugar de origem tenha se tornado um hábito raro, desde que ele se tornou um diplomata.

É possível dizer que o âmbito doméstico de Aracy era o espaço onde se cultivavam as práticas alimentares da culinária cosmopolita, enquanto a literatura de Guimarães Rosa era o espaço próprio para preservar os hábitos da culinária regionalista. Essas preferências à mesa expressavam as origens e destinos dos Rosa.

Mas o que comiam seus altos personagens, homens do sertão? Leonardo Arroyo (I984), ao analisar a cultura popular em Grande sertão: veredas, destaca a alimentação dos jagunços. A busca da dieta dos prazeres, contudo, nos levou ao encontro dos romances mais sensuais de Guimarães Rosa, "Dão-Lalalão" e "Buriti”, presentes no livro Noites do sertão. Isso não é à toa: "noite" aqui pode muito bem significar amor e desejo. A noite desperta no sertão toda a transgressão de que a sexualidade é possível.

"Dão-Lalalão" nos conta do ex-boiadeiro e matador de jagunços Soropita, que 
tomara para se casar a ex-prostituta Doralda. No caminho de volta para a casa, de Andrequicé ao Ão, Soropita encontra seu antigo amigo Dalberto. Teme agora que ele ou os homens de sua comitiva pudessem ter conhecido o passado de sua mulher. Desenrola-se a partir disso toda a trama do ciúme.

A caracterização das personagens, em suas preferências à mesa, ocorre sob a influência do passado que se quer ocultar. Soropita é descrito com suas armas, matador de muitas mortes, que carregava no próprio corpo as cicatrizes do passado. "Soropita não comia galinha, se visse matar. Carne de porco, comia; mas, se podendo, fechava os ouvidos, quando o porco gritava guinchante, estando sendo sangrando. E o sangue fedia, todo sangue fedor triste" (ROSA, 2006, p. 477). Doralda é caracterizada, como mulher, muito mulher, pelo cheiro e pelo riso. E o que dizer de suas maneiras à mesa? "Doralda tinha apetite contente em mêsa, com distintas maneiras" (ROSA, 2006, p. 480). "Soropita não aceitava carne assada malmal, fêbras vermelhas, sangue se vendo. Doralda guisava para ele tudo de que ele gostava, nunca se esquecia: 'Tu entende, Bem: comer é estado, daí vem uma alegria...' Mordia” (ROSA, 2006, p. 480).

Depois de reencontrar Dalberto, Soropita conduz o amigo para casa e o convida para jantar. Mas ele não tinha com que se preocupar. Dalberto, com a boca cheia de quiabo com galinha, lágrimas em muitos olhos, que a comida tinha levado pimenta, não apunha malícia ao ver Doralda. O amigo hospedador lhe oferecera pouso. Doralda confirmava, cortando a carne de porco com faca e garfo. Soropita se levantava para buscar cerveja. E Dalberto se servia ele mesmo de angu. Depois do doce, Soropita queria prestar as palavras amáveis na cozinha.

Doralda oferecia café e tinha aceitado conversa com Dalberto a respeito de Montes Claros! Sabia, portanto. Dúvida não tinha mais. Dalberto tinha estado com ela. Ele mesmo, Soropita, não tinha conhecido Doralda assim? Até imaginasse que ele não conhecia o passado dela e iludido se casara. Ah, isso não. Soropita era homem com mortes afamadas!

Doralda era dele, porque ele queria e podia, a cães, tinha desejado. Idiota, não. Mas, então, que ficasse sabendo o Dalberto. Ali, de praça, sabendo e aprendendo que o passado de um ou de uma não indenizava nada, que tudo só está por sempre valendo é no desfecho de um falar e gritar o que quer! (ROSA, 2006, p. 530).

Agora, Soropita está à altura de si mesmo e pode decifrar o próprio destino. É o que mostra Bento Prado Jr. (2000) no texto “O destino decifrado". Soropita e Doralda tinham ambos um passado a ocultar. Ele não podia ver o sangue da carne, como matador de jagunços que era. Ela tinha apetite contente em mesa, para quem comer é um estado de alegria, como prostituta que havia sido. É o ciúme de Soropita que permite trazer o passado proibido de Doralda para o presente. Somente ao reconciliar-se com seu destino, ele é capaz de conversar sobre a verdade do passado dela.

Se "Dão-Lalalão" apresenta o prazer da mesa como um desejo oculto do sujeito que precisa ser decifrado para que se possa assumir o próprio destino, em "Buriti", o prazer da mesa é organizado pelo falo que domina a paisagem em seu papel de representante do desejo.

A história de "Buriti” começa com as lembranças de Miguel, quando retorna à 
fazenda Buriti Bom, após a primeira visita. Ele é esperado como aquele que irá pedir a mão de Glorinha. Depois, a história é recontada pela perspectiva de Lalinha, que havia sido raptada pelo sogro, iô Liodoro, após ter sido abandonada pelo marido, à espera de que um dia o filho voltasse para casa.

Quando se referia aos moradores do Buriti Bom, nhô Gualberto Gaspar comentava que iô Liodoro, por mais rijo e fogoso que fosse, não queria se casar pela segunda vez. Ali, havia as duas filhas moças: uma tão diversa da outra. Maria da Glória era como se estivesse "no ponto justo, escorrendo caldo, com todos os perfumes de mulher para ser noiva urgente” (ROSA, 2006, p. 642). Maria Behú não acharia quem quisesse se casar com ela, triste e feia que era. Não deixava de reparar também que o compadre iô Liodoro "carece mais de lazer de catre do que um outro, muito mais" (ROSA, 2006, p. 674). "Ele é viúvo são, sai aos repentes por aí, feito cavalo inteiro em cata de éguas, cobra por sua natureza. Garanhão ganhante... Dizem que isso desce de família, potência bem herdada" (ROSA, 2006, p. 675).

Toda a potência da família parece ter sido herdada da Vovó Maurícia e do Vovô Faleiros. Ela é quem diz: "A gente deve de ter muitos filhos, quantos vierem, e com amor de bem criar, desistidos cuidados de se ralar, sem sobrossos: que Deus é estável. Mas a gente se casa não é só para isso não - a gente se casa será é para lua-de-mel e luas-de-méis!...” (ROSA, 2006, p. 720).

A sexualidade aparece aqui organizada por um símbolo fálico que domina a paisagem. O Buriti-Grande era o maior, perante tudo, um tanto fora da ordem da paisagem. "O Buriti-Grande... podendo ser de pedra. [...] Plantava em poste o corpulento roliço. [...] E, em noite clara, era espectral - um só osso, um nervo, músculo" (ROSA, 2006, p. 692). Para a psicanálise, o falo não se confunde com o pênis, mas representa a função simbólica do desejo. Tanto o desejo do eu e do outro, quanto a diferença sexual entre ser ou ter o falo. O Buriti-Grande representava ainda a Árvore da Vida, símbolo sagrado da garantia da vida eterna. Aquele palmeirão descomunado corria o risco de que o derrubassem ou o deixassem derribar. Morto, porém, se oferece a nós em corpo e sangue, entrega a si mesmo no pão e no vinho. Deitado, cavavam-lhe no lenho um cocho, que ia se derramar até se encher de "róseo sangue doce, que em vinho se fazia; e a carne de seu miolo dava-se transformada no pão de uma grumosa farinha" (ROSA, 2006, p. 680-68I). O motivo bíblico da Árvore da Vida é representado no sertão. Comer os frutos do Buriti-Grande permite a renovação da vida.

Aquela sociedade patriarcal, ao insistir em manter os laços de família, não permitia que a vida fosse renovada. Tendo sido feita prisioneira na fazenda, Lalinha via o tempo passar pelo ciclo das festas anuais. Durante o Natal, armava-se o presépio para exultar o nascimento de Jesus Nosso Senhor. Matavam boi, matavam porco. Era a festa. Iô Ísio trazia o doce-de-buriti, "aquele doce granulado e oleoso, marrom-claro, recendendo a tamarindo e manchando-se, no oscilar, como azeite-de-dendê: assim só as mulheres sertanejas acertavam de o preparar, com muito amor" (ROSA, 2006, p. 748-749). Depois da meia-noite, todos vinham à mesa para bem comer e beber. No São-João, toda gente dançava e cantava ao redor da fogueira. Mandioca e batata-doce assavam no borralho. Rejubilava o ato de comer, quando as mulheres da cozinha serviam os pratos fundos repletos de canjica "de leite, coco, queijo, manteiga e amendoim, com paus de canela nadantes” (ROSA, 2006, p. 765). Lalinha queria partir, 
pois tudo ali parecia impedir os movimentos do futuro. E, agora, nem sabia bem como, começara a jogar cartas com o sogro. Ali não acontecia nada, era como se todo desejo morresse em semente.

Um dia, aconteceu. Uma noite, ela pôde conversar com iô Liodoro. "Assim tão linda, a gente mesmo acha, faz gosto...'[...] 'O senhor acha? De verdade?' [...] 'Linda!' [...] 'A boca...' [...] 'Os olhos...' [...] 'E o corpo, o senhor gosta? A cintura?' [...] Sim, a cintura, o busto, os seios, as mãos, os pés... Devagar, a manso, falavam tudo nela, os olhos e as palavras dele quentemente a percorriam" (ROSA, 2006, p. 787-788). Oferecia-se em palavras. Era um jogo erótico, como se a voz dele a pegasse no corpo. Mas não poderia tocá-la.

E Nhô Gualberto Gaspar dormiu um dia na casa. Após o jantar, os risos. Glorinha, atirada e saída. Nhô Gaspar, homem que escancarava a boca e se coçava nas pernas. Aquilo enojava. Iô Liodoro pediu o restilo para beber com o compadre Gual. Mas assim, num contentamento, quis mais. Mandou que Glorinha trouxesse o vinho. "O vinho-doce espesso, no cálice, o licor-de-buriti, que fala os segredos dos Gerais, a rolar altos ventos, secos ares, a vereda viva” (ROSA, 2006, p. 797). Lala e Glória também bebiam. Ria-se e era bom. Uma vontade de gozar a matéria ávida da vida. E, tomando o cálice, beberam todos em memória da vereda viva o vinho de buriti, que conta os segredos dos Gerais.

Certa noite, houve uma mudança! Iô Liodoro lhe perguntou se ela não estaria cansada da vida da roça, querendo voltar para o conforto da cidade. Mais tarde, ela soube que chegara uma carta de Irvino, contando que agora teria um filho! Concluiu: "Ele sabe que não sou mais de seu Filho... [...] Só me quer, só me aceita, através do Filho!” (ROSA, 2006, p. 8II).

Antes da partida, Glorinha revelou seu segredo. Não era mais virgem, tinha se tornado uma mulher. Pois sabia que Miguel não iria mais voltar. Lala decidiu então buscar Miguel, para a salvação de Glorinha! Falou com iô Liodoro que tinha que ir embora. Tudo terminado. Um nada. E, de repente, uma onda de viver. Ela falou-lhe quase ao ouvido: "Você, escuta: sou livre, vou-me embora. Na cidade, vou ter homens, amantes... Você gosta de mim, me acha bonita, você me deseja muito, eu sei. Pois, se quiser, se vale a pena, estou aqui. Esta noite, deixo a porta do quarto aberta...” (ROSA, 2006, p. 820). Agora se despia. Ia esperá-lo sobre as roupas do leito, em carne. Aí, de repente, a porta se abria. Era ele, que vinha para conhecê-la. No final da história, Miguel volta à fazenda para pedir a mão de Glorinha. "Vigia: que palmeira de coragem!” (ROSA, 2006, p. 828). O rapaz admirava a liberdade do Buriti-Grande para aprender a vida.

O Buriti-Grande exigia que a vida fosse renovada. Iô Liodoro representava uma sociedade patriarcal, insistindo em manter os laços de família, que impediam os movimentos do futuro. No santuário do Buriti Bom, a história do patriarcado pôde ser dissolvida com o mito dionisíaco, como mostra Luiz Roncari (20I3). Beber o vinho de buriti, que contava os segredos do sertão, possibilitou a incorporação da força da natureza para que a vida se renovasse. O Buriti-Grande, símbolo fálico por excelência, exigia que se tivesse muita coragem para responder ao enigma do desejo.

O reencontro com a cozinha mineira só ocorreu após analisarmos os romances “Dão-Lalalão" e "Buriti”. Então, foi possível encontrar as comidas mineiras dos dias 
comuns - quiabo com galinha, carne de porco com angu - e dos dias de festas canjica na noite de São João. Todos pratos mineiros, não sendo exclusivos da gente de Minas. Talvez, o licor de buriti, que guarda a memória da vereda viva, seja uma especialidade regional. Contudo, toda e qualquer receita para o amor somente será eficaz, como ensina Noites do sertão, se puder integrar o passado no presente para responder ao enigma da existência, bem como permitir os movimentos do futuro ao incorporar a força do desejo.

\section{SOBRE A AUTORA}

TÂNIA BIAZIOLI é psicóloga, mestra e doutora em Psicologia Social pelo Instituto de Psicologia da Universidade de São Paulo (IP/USP), onde defendeu a tese sobre A quebra entre o passado e ofuturo na cozinha caipira (2018).

E-mail: tania_biazioli@yahoo.com.br

https://orcid.org/0000-0002-5460-4964

\section{REFERÊNCIAS}

ABDALA, Mônica Chaves. Receita de mineiridade: a cozinha e a construção da imagem do mineiro. Uberlândia: EDUFU, 2007

ABRAHÃO, Eliane Morelli. A escrita culinária: permanências e transformações. Campinas (I863-I940). In: PINHEIRO, Joaquim; SOARES, Carmen (Coord.). Patrimônios alimentares de aquém e além-mar. Coimbra: Imprensa da Universidade de Coimbra, 20I6, p. 47-62.

ALGRANTI, Leila Mezan. História e historiografia da alimentação no Brasil (séculos XVI-XIX). In: CAMPOS, Adriana Pereira et al. (Org.). A cidade à prova do tempo: vida cotidiana e relações de poder nos ambientes urbanos. Vitória: GM Editora; Paris: Université de Paris-Est, 2010.

ARQUIVO IEB/USP, Fundo Aracy de Carvalho Guimarães Rosa. Caderno. Receita Culinária. Códigos dos documentos: ACGR-0046, ACGR-0047, ACGR-0048, ACGR-0050.

ARQUIVO IEB/USP, Fundo Aracy de Carvalho Guimarães Rosa. Cardápio. Códigos dos documentos: ACGR0003, ACGR-I643, ACGR-I3II, ACGR-I434, ACGR-I367.

ARROYO, Leonardo. A cultura popular em Grande Sertão: Veredas. Rio de Janeiro: José Olympio Editora, I984.

CAMARGOS, Márcia; SACCHETTA, Vladimir. À mesa com Monteiro Lobato. Rio de Janeiro: Senac Nacional, 2008.

CANDIDO, Antonio. Os parceiros do Rio Bonito. São Paulo: Duas Cidades/Editora 34, 2001.

CARNEIRO, Henrique Soares. Comida e sociedade: uma história da alimentação. Rio de Janeiro: Campus, 2003.

CARVALHO, Ana Cecília de. O livro neurótico das receitas. Belo Horizonte: Artesa, 2012. 
CASCUDO, Luís da Câmara. História da alimentação no Brasil. Belo Horizonte: Editora Itatiaia. São Paulo: Universidade de São Paulo, I983.

DÓRIA, Carlos Alberto. A cozinha nacional antes da feijoada. In: Cozinheiro nacional. São Paulo: Ateliê Editorial/Senac São Paulo, 2008, p. 7-26.

ESSE viver ninguém me tira. Direção de Caco Ciocler. Brasil: BSB Serviços Cinevideo Ltda., 20I4.

FREUD, Sigmund. Três ensaios sobre a teoria da sexualidade (I905). In: . Obras completas, volume 6.

Tradução Paulo César de Souza. São Paulo: Companhia das Letras, 2016.

FREYRE, Gilberto. Manifesto regionalista. 7. ed. Recife: Fundaj/Editora Massangana, I996. . Prefácio à $3^{\mathrm{a}}$ edição. In: Açúcar: uma sociologia do doce, com receitas de bolos e doces do

Nordeste do Brasil. São Paulo: Companhia das Letras, I997.

. Casa grande ersenzala: formação da família brasileira sob o regime da economia patriarcal. 5I. ed.

São Paulo: Global, 2006.

FRIEIRO, Eduardo. Feijão, angu e couve. Belo Horizonte: Itatiaia; São Paulo: Universidade de São Paulo, I982.

HERRMANN, Fabio; MINERBO, Marion. Creme e castigo. Sobre a migração dos valores morais da sexualidade à comida. In: CARONE, Iray (Org.). Psicanálise de fim de século: ensaios críticos. São Paulo:

Hacker Editores, I998.

LAURIOUX, Bruno. Cozinhas medievais (séculos XIV e XV). In: FLANDRIN, Jean-Louis; MONTANARI, Massimo (Org.). História da alimentação. 8. ed. São Paulo: Estação Liberdade, 2015.

LODY, Raul. À mesa com Gilberto Freyre. Rio de Janeiro: Senac Nacional, 2004.

MENESES, Ulpiano Bezerra de; CARNEIRO, Henrique. A história da alimentação: balizas historiográficas. Anais do Museu Paulista, v. 5, jan.-dez. I997, p. 9-9I. https://doi.org/Io.I590/SoI0I-47I4I997000I00002. MINÉ, Elza; CAVALCANTE, Neuma. Memória da leitura e rememoração da viagem: cartas de João Guimarães Rosa para Aracy de Carvalho Guimarães Rosa. In: SCARPELLI, Marli de Oliveira Fantini (Org.). A poética migrante de Guimarães Rosa. Belo Horizonte: Editora UFMG, 2008, p. 426-443.

OUTRO sertão. Direção de Adriana Jacobsen, Soraia Vilela. Brasil: Instituto Marlin Azul, Galpão Produções, 2013.

POULAIN, Jean-Pierre. Sociologias da alimentação. Florianópolis: UFSC, 2006.

PRADO JR., Bento. O destino decifrado. Linguagem e existência em Guimarães Rosa. In: Alguns ensaios: filosofia, literatura e psicanálise. São Paulo: Paz e Terra, 2000.

RONCARI, Luiz. Buriti do Brasil e da Grécia: patriarcalismo e dionisismo no sertão de Guimarães Rosa. São Paulo: Editora 34, 2013.

ROSA, Aracy Guimarães. Breve conversa sobre Guimarães Rosa. Entrevista a Gilberto Cavalcanti. Jornal do Commercio, Rio de Janeiro, 20 jun. I965, p. 5.

ROSA, João Guimarães. “Dão-Lalalão” e "Buriti”. In: . Corpo de baile. Rio de Janeiro: Nova Fronteira, 2006.

SANTOS, Carlos Roberto Antunes dos. A alimentação e seu lugar na história: os tempos da memória gustativa. Revista História, Questões e Debates - Dossiê História da Alimentação, n. 42, Curitiba: Editora UFPR, 2005.

SOUZA, Eneida Maria; OTTE, Georg; MARQUES, Reinaldo Martiniano (Org.). “Diário de guerra” de João Guimarães Rosa. Documento do Acervo de Escritores Mineiros da Universidade Federal de Minas Gerais.

SCHPUN, Mônica Raisa. Justa - Aracy de Carvalho e o resgate dos judeus: trocando a Alemanha nazista pelo Brasil. Rio de Janeiro: Civilização Brasileira, $20 I I$.

WEINBERG, Cybelle. Sabores inconscientes: receitas sem culpa. São Paulo: Sá Editora, 2008. 